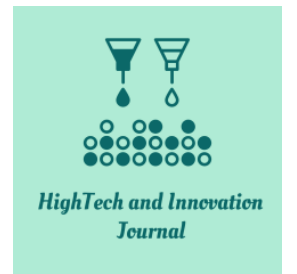

ISSN: $2723-9535$

\title{
Ab-initio Study of Structural and Electronic Properties of Perovskite Nanocrystals of the $\mathrm{CsSn}\left[\mathrm{Br}_{1-x} \mathrm{I}_{\mathrm{x}}\right]_{3}$ Family
}

\author{
D. D. Nematov ${ }^{1,2 *}$, Kh. T. Kholmurodov ${ }^{3}$, D. A. Yuldasheva ${ }^{2}$, \\ Kh. R. Rakhmonov ${ }^{1}$, I. T. Khojakhonov ${ }^{2}$ \\ ${ }^{1}$ S.U. Umarov Physical-Technical Institute of the National Academy of Science of Tajikistan, Dushanbe, Tajikistan. \\ ${ }^{2}$ Osimi Tajik Technical University, 724000, Dushanbe, Tajikistan. \\ ${ }^{3}$ Joint Institute for Nuclear Research, 141980, Dubna, Moscow Oblast, Russia.
}

Received 12 December 2021; Revised 02 February 2022; Accepted 11 February 2022; Available online 19 February 2022

\begin{abstract}
In this study, by means of quantum-chemical calculations within the framework of density functional theory, we considered a number of structural and electronic properties of nanocrystals of the $\mathrm{CsSn}\left[\mathrm{Br}_{1-x} \mathrm{I}_{x}\right]_{3}$ (systems $\mathrm{CsSnBr}_{3}$, $\mathrm{CsSnBr}_{2} \mathrm{I}, \mathrm{CsSnBrI}_{2}$ and $\mathrm{CsSnI}_{3}$ ) and discussed the effect of iodine concentration on the geometry and electronic properties of these materials. The exchange correlation effects of electrons were taken into account by the LDA, GGA and the modified Becke-Jones exchange correlation potential (mBJ). The results obtained in the framework of the DFT$\mathrm{mBJ}$ and the Wien2k packages are in good agreement with the data from experimental measurements and open up the possibility of accurately predicting a number of fundamental properties of perovskite-like complex structures and the development of new materials.
\end{abstract}

Keywords: Band Gap; Density Functional Theory; Electronic Structure; Perovskite; Wien2k Package.

\section{Introduction}

The possibilities of converting solar energy and other unconventional forms of energy into electricity are considered in the context of projected global energy needs for the $21^{\text {st }}$ century. Therefore, a very urgent task facing scientists and engineers today is the study of a number of electronic, optical, thermal, and other characteristics of new materials with the aim of their application in solar energy. To successfully make the transition from fossil fuels to renewable energies and confront climate change and pollution, we can no longer rely solely on existing materials, but must focus on synthesizing other classes of materials with improved properties. Moreover, the demand for energy is constantly increasing with population growth, and the gap between demand and supply also widens over time.

Conventional energy production methods will no longer be able to meet the world's energy needs. Therefore, unconventional measures, including the creation of photovoltaic devices, wind farms, and moisture-to-electricity converters, are of great interest, and for the implementation of these tasks and the transition to Green Energy, countries around the world allocate a huge amount of money and support scientists and engineers to strengthen their research work. The effect of converting light into electricity was discovered back in 1839 by Alexander Edmond Becquerel, after which Charles Frits and Jacamo Luigi made the first attempt to create the first light-to-electricity converter, but

* Corresponding author: dilnem@mail.ru

\section{doi) http://dx.doi.org/10.28991/HIJ-2022-03-02-03}

$>$ This is an open access article under the CC-BY license (https://creativecommons.org/licenses/by/4.0/).

(C) Authors retain all copyrights. 
this unique discovery did not really attract the attention of researchers due to the low coefficient transformation. Over the years, attempts have been made to increase the photoelectric conversion factor of solar cells, which were created on the basis of silicon, gallium arsenide, and other semiconductor materials. Recently, as a tradition for the creation of solar panels, silicon composites have been widely used due to their unique electrophysical properties, such as the width of the requested area and the ability to absorb light. However, at the moment, the maximum conversion efficiency (efficiency) of commercially available silicon converters is only 14-15\% [1]. Moreover, the technology for the production of traditional silicon-based solar cells is advanced, but there are some problems, such as high cost and environmental pollution, that need to be addressed. Recently, as a tradition for the creation of solar cells, silicon composites have been widely used due to their unique electrophysical properties, such as bandgap and light absorption capacity. However, at the moment, the maximum conversion efficiency (efficiency) of commercially available silicon converters is only 14-15\% [1]. Moreover, the technology for the production of traditional silicon-based solar cells is advanced, but there are some problems, such as high cost and environmental pollution, that need to be addressed.

In 2013, Science magazine reported on the possibility of using perovskites in solar cells [2]. According to the National Laboratory for Renewable Energy Sources (NREL), perovskites are also widely used in memory devices, LEDs, diodes for ultra-high-power lasers, etc. [3], due to their low cost, high absorption coefficient, high mobility of charge carriers, composite flexibility, high stability, and adjustable material structure. The only natural perovskite, calcium titanate $\left(\mathrm{CaTiO}_{3}\right)$, was discovered by Gustav Rose in 1839 and was named perovskite in honor of Count L.A. Perovsky. Later, the artificial synthesis of these structures began with the general formula $\mathrm{ABX}_{3}$, where $\mathrm{X}=F^{-}, \mathrm{Cl}^{-}$, $\mathrm{Br}^{-}, I^{-}$and $\mathrm{O}^{2-}$. Elements $\mathrm{A}$ and $\mathrm{B}$ are two cations of different sizes, shown in Figure 1. The elements in the red box are used for the A-site, and the elements in the pink and brown boxes are used for alloying the A-site. The elements in the blue box are used for the B-site, and the elements in the green and blue boxes are used for doping the B-site [4].

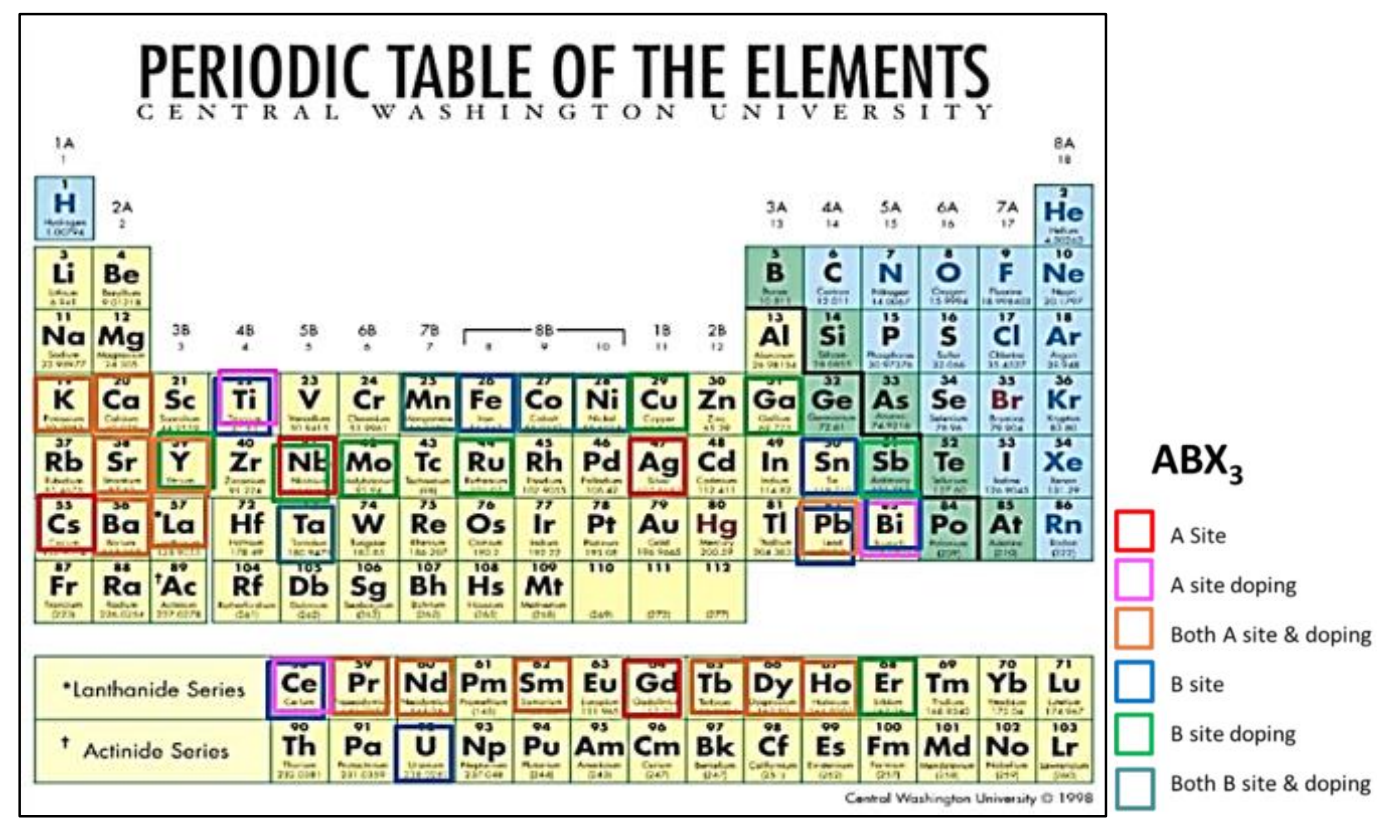

Figure 1. Components of the $\mathrm{ABX}_{3}$ system

The feature and prospect of the use of halide-based perovskites is that they can be tuned either by changing the content of halides or by using the size of the cations to obtain the optimal bandgap for photovoltaic applications. Moreover, the efficiency of perovskite panels has already been exceeded by $26.7 \%$ [5]. However, despite the rapid progress made over the past few years in terms of conversion efficiency, understanding of the fundamental properties of perovskites is rather limited. Following this, the aim of this work is a quantum-chemical study of the geometric and electronic properties of I-doped perovskite nanostructures based on $\mathrm{CsSnBr3}$ in order to find the regularity of the change in their properties under the influence of iodine concentration, as well as to reveal the expediency of further experimental study of the properties of these nanocrystals.

\section{Materials and Methods}

$\mathrm{Ab}$ initio quantum-chemical calculations within the framework of the density functional theory [6] were implemented in the Wien2k package [7]. The DFT is a method based on ab initio calculation initially proposed by Hohenberg [8], Kohn and Sham [9] which has the advantage to not rely on any experimental parameter. The idea of this method is to replace the interacting electronic system by a fictitious non-interacting electronic system which gives the same electronic density as the interacting system. The $\mathrm{XC}$ potential affecting the non-interacting electronic system 
can be obtained from the XC energy which is only a functional of the electronic density. However, no exact functional exists but many approximative functionals have been developed, for example, LDA, GGA. The object under study was the orthorhombic structures of nanocrystals of the $\mathrm{CsSn}\left[\mathrm{Br}_{1-x} \mathrm{I}_{x}\right]_{3}$ family (systems $\mathrm{CsSnBr}_{3}, \mathrm{CsSnBr}_{2} \mathrm{I}, \mathrm{CsSnBrI}_{2}$ и $\mathrm{CsSnI}_{3}$ ). The radius of the Mufftin sphere (RMT) for Cs, Sn and I was taken as $2.5 \mathrm{a}_{0}$, and for Br $-2.07 \mathrm{a}_{0}$, where $\mathrm{a}_{0}$ is the Bohr radius. Nevertheless, the crystal structures of the materials under study are shown in Figure 2.

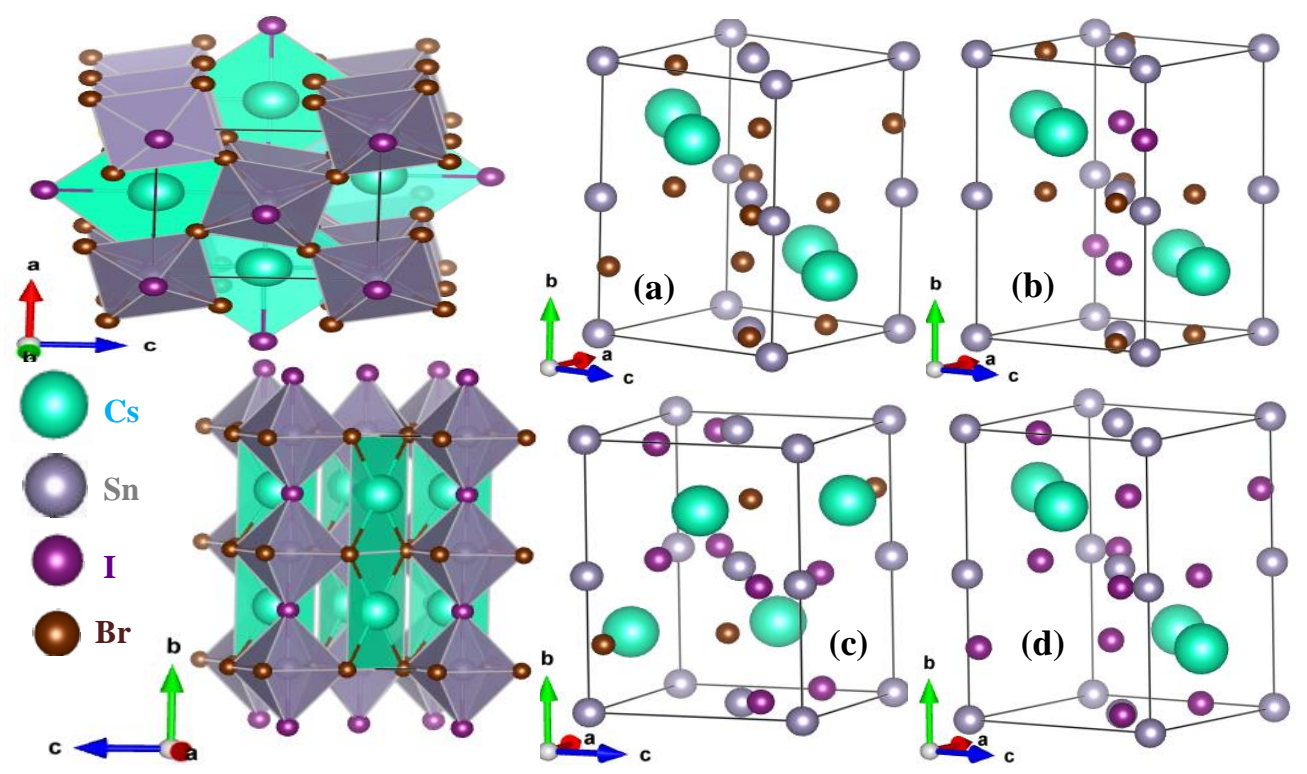

Figure 2. Schematic illustration of crystal structures of (a) $\mathrm{CsSnBr}_{3}$, (b) $\mathrm{CsSnBr}_{2} \mathrm{I}$, (c) $\mathrm{CsSnBrI}_{2}$ and (d) $\mathrm{CsSnI}_{3}$

The valence wave functions inside the MT sphere were expanded to $1_{\max }=10$, and the charge density was expanded in a Fourier series up to Gmax (boron-1). For sufficiently good convergence in the parameters of the total crystal lattice energy, all atomic geometry optimizations for the orthorhombic unit cell of $\mathrm{CsSn}_{3}\left[\mathrm{Br}_{1-x} \mathrm{I}_{x}\right]_{3}$ were performed using k-points generated by uniform grid parameters $3 \times 2 \times 3$. In addition to using the LDA and GGA approximations, the study of electronic properties required the use of the modified Becke-Johnson potential (TB-mBJ) [10], the formulation of which is given as follows:

$E_{x c}^{m B J}(r)=c E_{x}^{B R}(r)+(3 c-2) \frac{1}{\pi} \sqrt{\frac{5 k(r)}{6 \rho(r)}}$

where $k(r)$ is the kinetic energy density according to the Kohn - Sham equation, is the spin-dependent electron density, and $E_{x}^{B R}$ - is the Becke - Roussel exchange functional (BR). $c$, is the added parameter by Tran and Blaha to the mBJ potential.

TB-mBJGGA and TBmBJ + LDA potentials, whose mBJ exchange potential is available in the LIBXC interface library [11], are used in combination with lattice parameters optimized by the GGA and LDA approximations.

\section{Results and Discussion}

\subsection{Structural Properties}

Determination of the structural specification (optimized lattice constants (a, b, c), volume (V) and angles between $\mathrm{a}, \mathrm{b}$ and $\mathrm{c}$ ) is inevitable for describing the structural properties of materials. The equilibrium lattice parameters of the materials under study are determined after optimization, where all these materials have the space group Pnma (62). Equilibrium lattice parameters were obtained by approximating the total energy as a function of the normalized volume, according to the equation of state of the ground state (EOS), the analytical expression of which is determined using the Birch-Murnaghan approximation [12]:

$E(\mathrm{~V})=E_{0}+\frac{9}{8} B_{0} V_{0}\left[\left(\frac{V_{0}}{V}\right)^{2 / 3}-1\right]^{2}+\frac{9}{16} B_{0}\left(B_{0}{ }^{\prime}-4\right) V_{0}\left[\left(\frac{V_{0}}{V}\right)^{2 / 3}-1\right]^{3}$

where $\mathrm{E}_{0}$ - is the DFT ground state energy. $\mathrm{B}_{0}$ - bulk modulus, $\mathrm{B}_{0}{ }^{\prime}$ - pressure derivative of the volumetric modulus $\left(B^{\prime}=(\partial B / \partial P)_{T}\right), \mathrm{V}$ - is the volum cell, $\mathrm{V}_{0}$ - equilibrium volume, that is, when the system is in a relaxing (ground) state.

A graphical description of $\mathrm{CsSnI}_{3}$ geometry optimization is shown in Figure 3. Similarly, for all perovskites of the $\mathrm{CsSn}\left[\mathrm{Br}_{1-x} \mathrm{I}_{x}\right]_{3}$ system, optimizations were performed and the energy of the system was determined as a function of volume. 


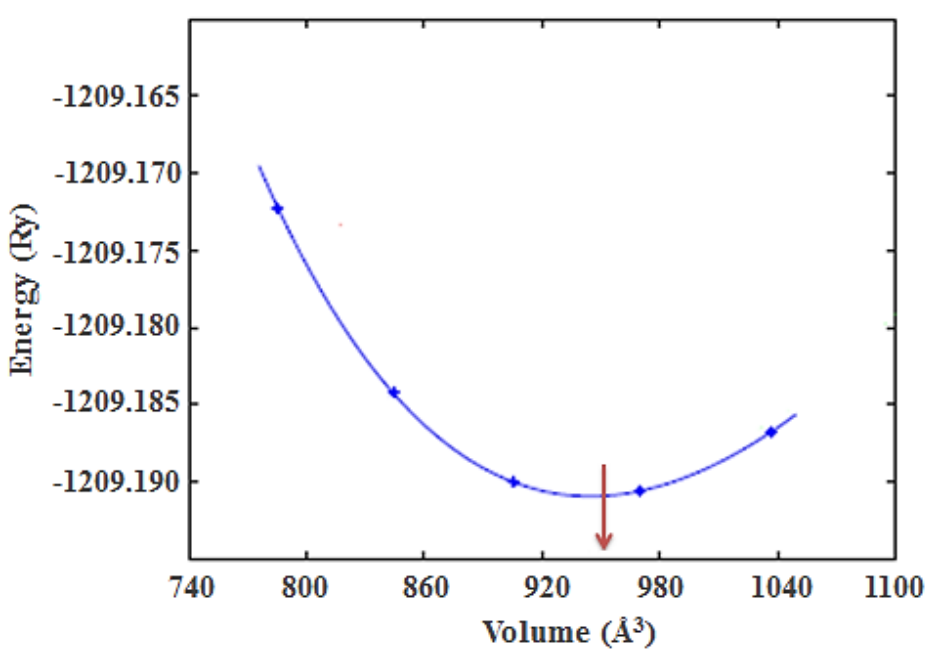

Figure 3. Graphical representation of geometry optimization. Energy-volume diagram for the orthorhombic CsSnI 3

The positions of the various atoms in the optimized structures are shown in Table 1.

Table 1. Atomic positions of $\mathrm{CsSnBr}_{3}, \mathrm{CsSnBr}_{2} \mathrm{I}, \mathrm{CsSnBrI}_{2}$ and $\mathrm{CsSnI}_{3}$ alloys

\begin{tabular}{|c|c|c|}
\hline & Atom & Atomic positions \\
\hline \multirow{3}{*}{$\mathrm{CsSnBr}_{3}$} & Cs & $(0.95,0.25,0.51),(0.04,0.75,0.48),(0.54,0.75,0.01),(0.45,0.25,0.98)$ \\
\hline & $\mathrm{Sn}$ & $(0,0,0),(0.5,0,0.5),(0,0.5,0),(0.5,0.5,0.5)$ \\
\hline & $\mathrm{Br}$ & $\begin{array}{l}(0.21,0.02,0.71),(0.78,0.97,0.28),(0.28,0.97,0.21),(0.71,0.02,0.78),(0.78,0.52,0.28),(0.21,0.47,0.71), \\
(0.71,0.47,0.78),(0.26,0.52,0,21),(0.99,0.75,0.95),(0,0.25,0.04),(0.5,0.25,0.45),(0.49,0.75,0.54)\end{array}$ \\
\hline \multirow{4}{*}{$\mathrm{CsSnBr}_{2} \mathrm{I}$} & Cs & $(0.99,0.25,0.50),(0,0.75,0.49),(0.5,0.75,0),(0.49,0.25,0.99)$ \\
\hline & $\mathrm{Sn}$ & $(0,0,0),(0.5,0,0.5),(0,0.5,0),(0.5,0.5,0.5)$ \\
\hline & $\mathrm{Br}$ & $\begin{array}{l}(0.19,0,0.69),(0.8,0.99,0.19),(0.3,0.99,0.19),(0.69,0,0.8),(0.8,0.5,0.3),(0.19,0.49,0.69) \\
(0.69,0.49,0.8),(0.3,0.5,0.19) .\end{array}$ \\
\hline & I & $(0,0.75,0.99),(0.99,0.25,0),(0.49,0.25,0.49),(0.5,0.75,0.5)$ \\
\hline \multirow{4}{*}{$\mathrm{CsSnBrI}_{2}$} & Cs & $(0.94,0.25,0.48),(0.58,0.75,0.51),(0.55,0.75,0.98),(0.44,0.25,0.01)$ \\
\hline & $\mathrm{Sn}$ & $(0,0,0),(0.5,0,0.5),(0,0.5,0),(0.5,0.5,0.5)$ \\
\hline & $\mathrm{Br}$ & $(0.98,0.75,0.93),(0.01,0.25,0.06),(0.51,0.25,0.43),(0.48,0.75,0.56)$ \\
\hline & I & $\begin{array}{l}(0.21,0.03,0.71),(0.78,0.96,0.28),(0.28,0.96,0.21),(0.71,0.03,0.78),(0.78,0.53,0.28),(0.21,0.46,0.71) \text {, } \\
(0.71,0.46,0.78),(0.28,0.53,0.21) .\end{array}$ \\
\hline \multirow{3}{*}{$\mathrm{CsSnI}_{3}$} & Cs & $(0.95,0.25,0.51),(0.05,0.75,0.48),(0.55,0.75,0.01),(0.44,0.25,0.98)$ \\
\hline & $\mathrm{Sn}$ & $(0,0,0),(0.5,0,0.5),(0,0.5,0),(0.5,0.5,0.5)$ \\
\hline & I & $\begin{array}{l}(0.2,0.03,0.7),(0.79,0.96,0.29),(0.29,0.96,0.20),(0.7,0.03,0.79),(0.79,0.53,0.29),(0.2,0.46,0.7), \\
(0.7,0.56,0.79),(0.29,0.53,0.2),(0.99,0.75,0.94),(0,0.25,0),(0.5,0.25,0.44)\end{array}$ \\
\hline
\end{tabular}

The calculated optimized lattice parameters (a, b, c, and V) and bond lengths for all structures are shown in Table 2 and the experimental data are compared.

Table 2. Comparison of calculated structural parameters with experimental ones

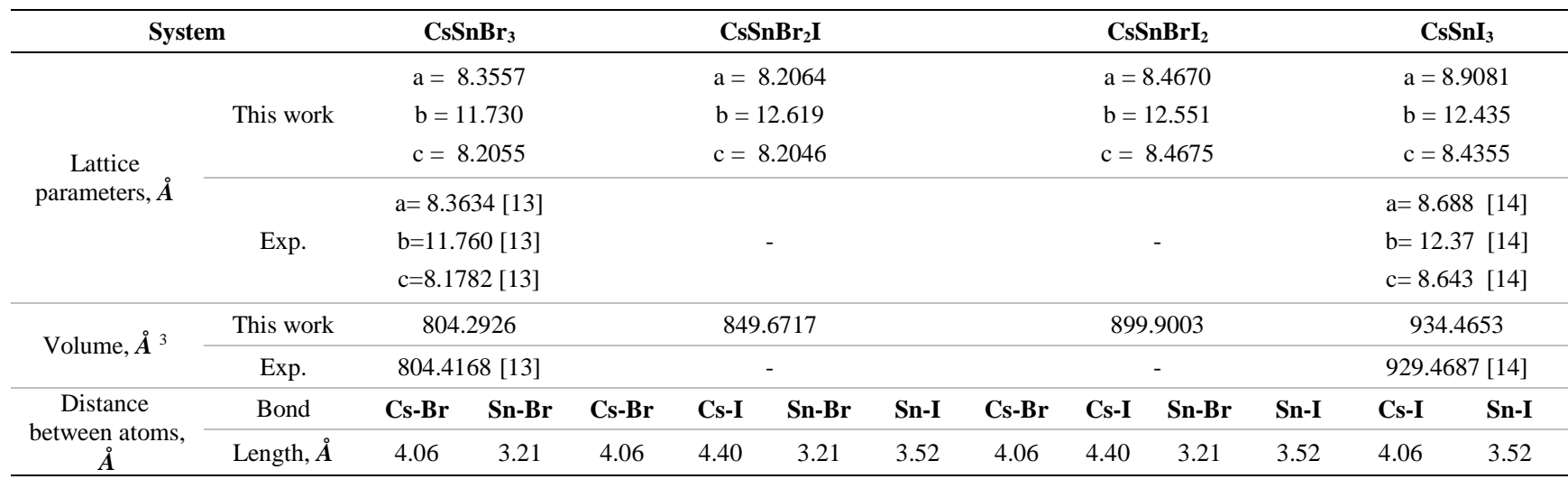


Comparison of the tabular data indicate that the calculated structural parameters for the unbiased systems $\mathrm{CsSnBr}_{3}$ and $\mathrm{CsSnI}_{3}$ are in good correlation with the experimental results (Table 2). However, there are no experimental data in the literature on the comparison of the lattice parameters of mixed perovskites $\mathrm{CsSnBr}_{2} \mathrm{I}$ and $\mathrm{CsSnBrI}_{2}$. Further, Figure 4 shows the dependences of the volume of nanocrystals of the $\operatorname{CsSn}\left[\mathrm{Br}_{1-x} \mathrm{I}_{x}\right]_{3}$ system on the iodine concentration.

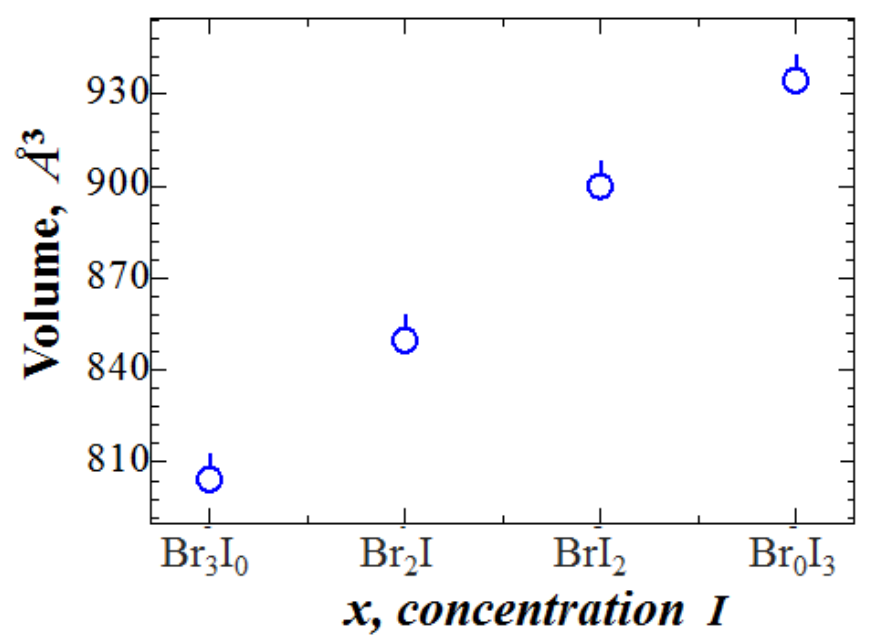

Figure 4. Change in the volume of the $\mathrm{CsSn}\left[\mathrm{Br}_{1-x} \mathrm{I}_{x}\right]_{3}$ system depending on the $\mathrm{Br} / \mathrm{I}$ ratio. Volume as a function of iodine concentration $(\mathbf{x})$

From the results obtained, listed in Table 1 and Figure 4, it can be noted that as the transition from $\mathrm{CsSnBr}_{3}$ to $\mathrm{CsSnI}_{3}$, that is, with an increase in the iodine concentration in the system, the volume of these nanocrystals increases linearly, which obeys Vegard's law.

In Figure 5(a) shows the X-ray diffraction patterns obtained from the optimized geometries of the studied materials, which were taken using the REFLEX program included in the Materials Studio software package, with CuKa radiation with a wavelength $\lambda=1.54 \AA$. According to the results, with an increase in the concentration of iodine in the system, the densification of X-ray peaks is observed and, accordingly, their shift towards small angles.
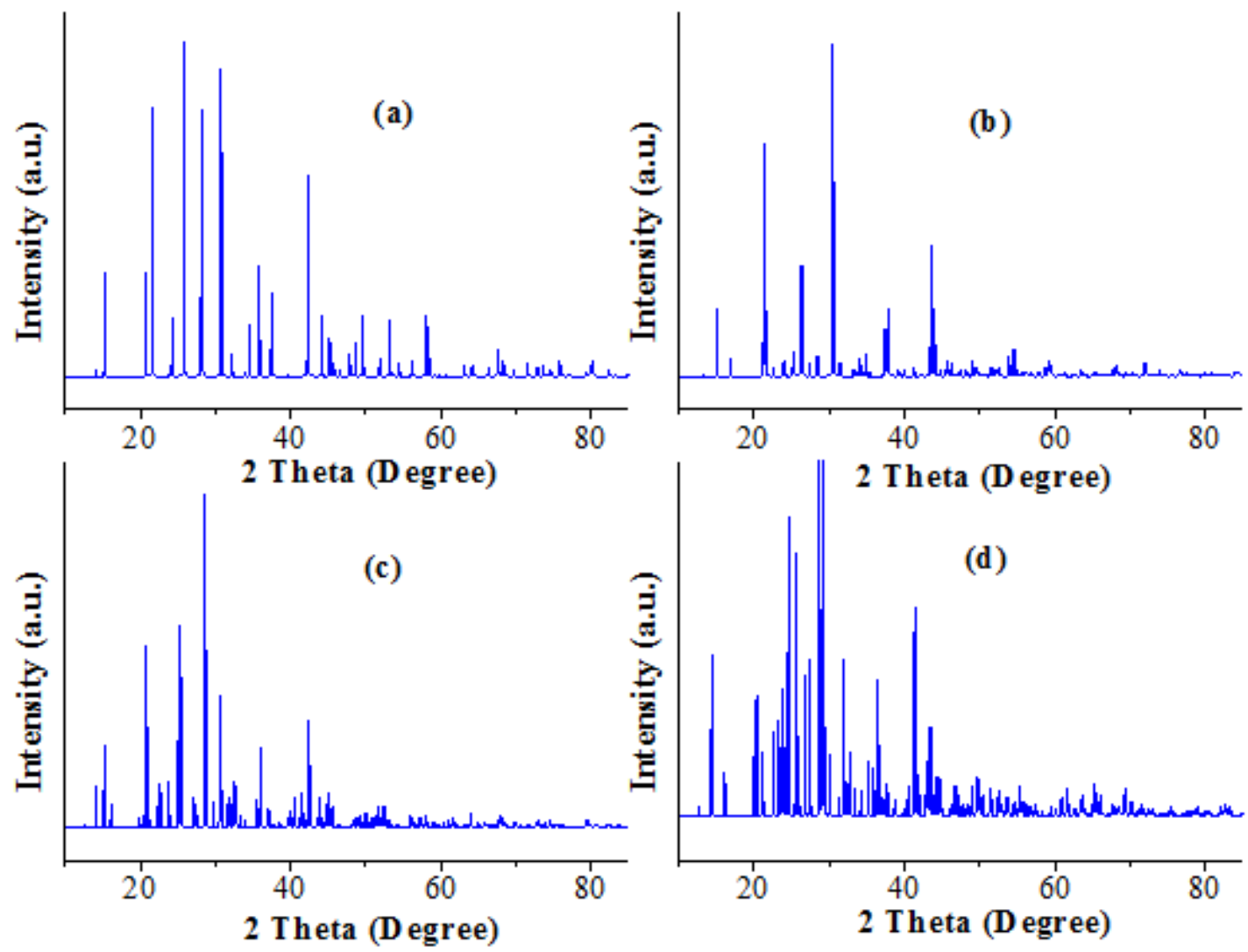

Figure 5. Theoretical powder diffractograms of (a) $\mathrm{CsSnBr}_{3}$, (b) $\mathrm{CsSnBr}_{2} \mathrm{I}$, (c) $\mathrm{CsSnBrI}_{2}$ and (d) $\mathrm{CsSnI}_{3}$ 
According to the results, the lattice constants we calculated for these materials are in good agreement with the experimental data (in all cases, less than 1\%) [13, 14], which testifies and confirms the correctness of the steps for optimizing the volume and, accordingly, the reliability of our calculations during further quantum-chemical analysis. calculations of the electronic properties of these materials.

\subsection{Electronic Properties}

Calculations of the electronic properties of the optimized structures and were based on density functional theory (DFT) using the Wien2k package. The exchange and correlation effects of electrons were taken into account by the exchange-correlation functionals LDA, GGA, and $\mathrm{mBJ}$, within which different values of the band gap were obtained for nanocrystals of the $\mathrm{CsSn}\left[\mathrm{Br}_{1-x} \mathrm{I}_{x}\right]_{3}$ system.

Band structure diagram tells us whether the material has direct or indirect band gap in addition to band gap value. Furthermore, it also tells us about the p-type, n-type or intrinsic nature of the semiconducting materials based on the position of Fermi level. Our results showed that the minima of the conduction band and the maxima of the valence band of all materials under study are located at the point $\Gamma$ and indicates a high symmetry (Figure 6), which indicates direct interband transitions in semiconductors, which is very favorable for light absorption. For pure cesium iodide, there is a band inversion at the point $\Gamma$, as reported in topological insulators. This phenomenon has been discussed in previous reports on other halide perovskites $[15,16]$.
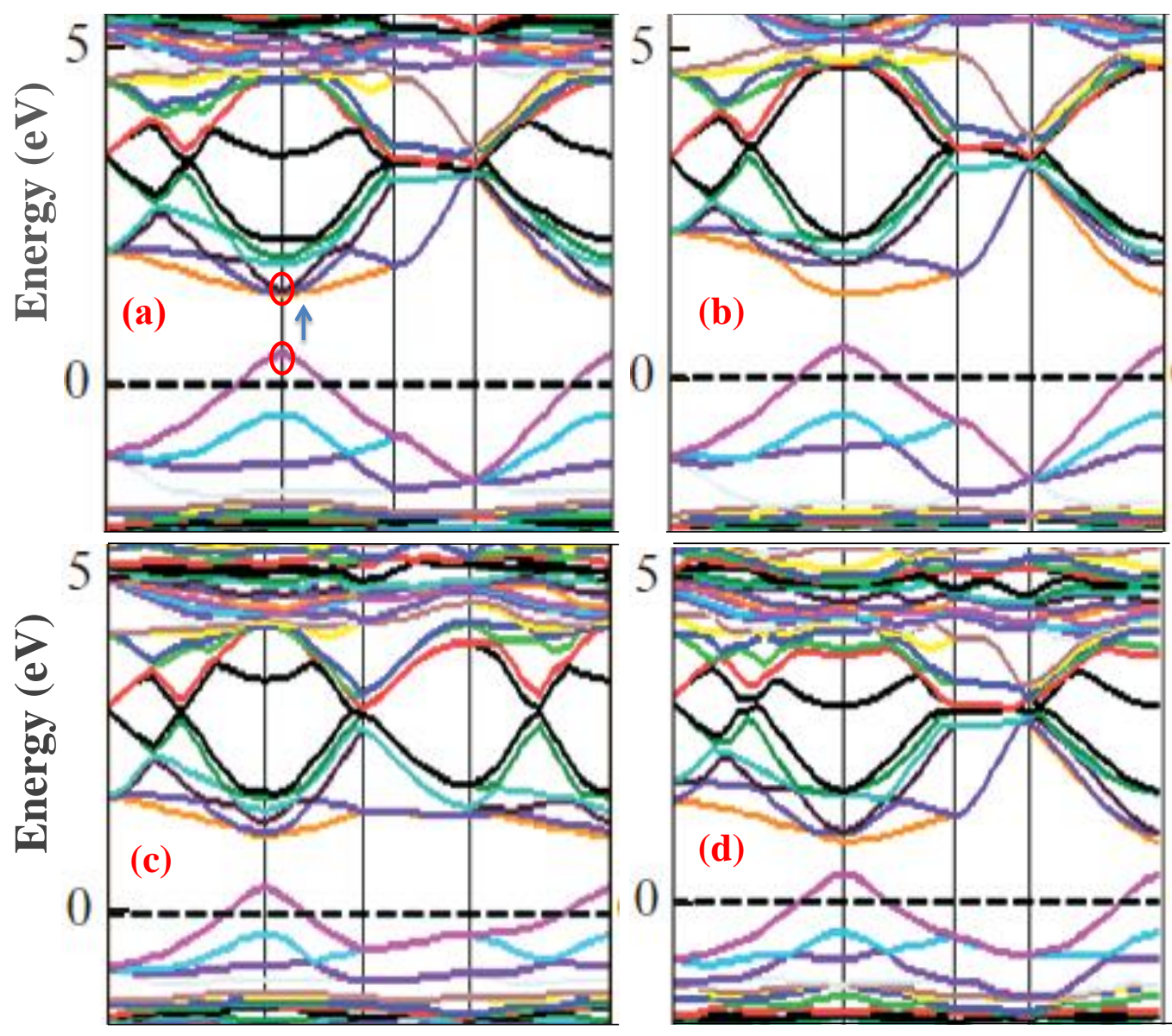

Figure 6. Electronic band structures of (a) $\mathrm{CsSnBr}_{3}$, (b) $\mathrm{CsSnBr}_{2} \mathrm{I}$, (c) $\mathrm{CsSnBrI}_{2}$ and (d) $\mathrm{CsSnI}_{3}$. The Fermi level is set to 0 for all band structures

As a rule, GGA and LDA significantly underestimate the band gap and band structure, therefore, in the tabular results and graphical dependencies presented in the work, in particular band structures and density of states, only the results of $\mathrm{mBJ}$ calculations are given, since numerous studies have confirmed the suitability of the mBJ functional for band gap estimates [17-28].

Because of the importance of iodides in photovoltaic applications, it is important to calculate as accurately as possible the parameters of the electronic structure of the systems under study, especially the band gap. The calculated band gaps are given in Table 3, from which it can be seen that the values of the band gap by the modified TB-mBJ functional are much more similar to experiment as compared to GGA and LDA. 
Table 3. Comparison of the calculation results of the band gap with the literature data

\begin{tabular}{|c|c|c|c|c|c|c|}
\hline & System & & $\mathrm{CsSnBr}_{3}$ & $\mathrm{CsSnBr}_{2} \mathrm{I}$ & $\mathrm{CsSnBrI}_{2}$ & $\mathrm{CsSnI}_{3}$ \\
\hline \multirow{5}{*}{ Band Gap, eV } & \multirow{3}{*}{ This work } & LDA & 0.91 & 0.82 & 0.73 & 0.61 \\
\hline & & GGA & 0.89 & 0.67 & 0.61 & 0.58 \\
\hline & & $\mathrm{mBJ}$ & 1.725 & 1.635 & 1.486 & 1.307 \\
\hline & \multicolumn{2}{|c|}{ Experiment } & $1.720[29]$ & - & - & $1.30[30]$ \\
\hline & \multicolumn{2}{|c|}{ Other calculations } & $1.01[31]$ & - & - & $0.885[32], 1.71[33]$ \\
\hline
\end{tabular}

The values of the band gap obtained by us for $\mathrm{CsSnBr}_{3}$ and $\mathrm{CsSnI}_{3}$ correspond with high accuracy to the literature data, especially the results of experimental measurements. However, for displaced perovskites $\left(\mathrm{CsSnBr}_{2} \mathrm{I}\right.$ and $\mathrm{CsSnBrI}_{2}$ ), there is no data for comparison in the literature. Figure 7 shows the graphs of the change in the band gap of the $\mathrm{CsSn}\left[\mathrm{Br}_{1-x} \mathrm{I}_{\mathrm{x}}\right]_{3}$ system depending on the concentration of iodine doping.

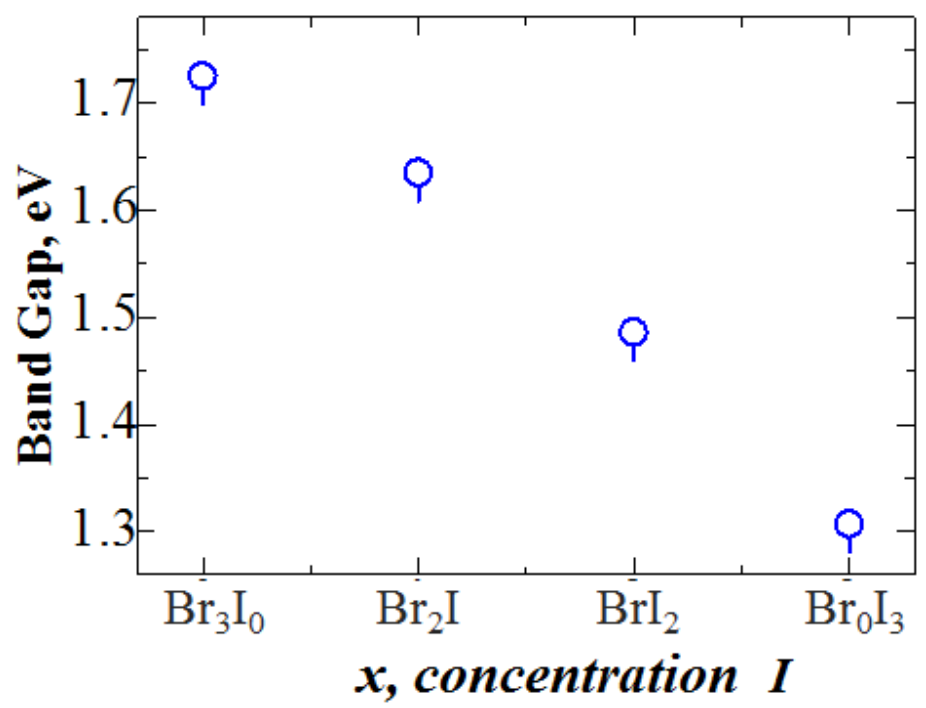

Figure 7. Calculated band gap as a function of $\mathrm{Br}$ concentration for $\mathrm{CsSn}\left[\mathrm{Br}_{1-x} \mathrm{I}_{x}\right]_{3}$

As shown in Figure 7, as the iodine concentration increases, the bandgap decreases linearly. That is, by controlling the iodine content, the bandgap can be adjusted to approach the optimal bandgap. Either way, the electronic properties of materials are based on the band gap, which lies in the density of electronic states (DOS). Therefore, understanding its formation becomes vital for the design and manufacture of optoelectronic devices. Figure 8 shows the total density of states (TDOS) for all members of the $\mathrm{CsSn}\left[\mathrm{Br}_{1-x} \mathrm{I}_{x}\right]_{3}$ system as a function of the band gap.

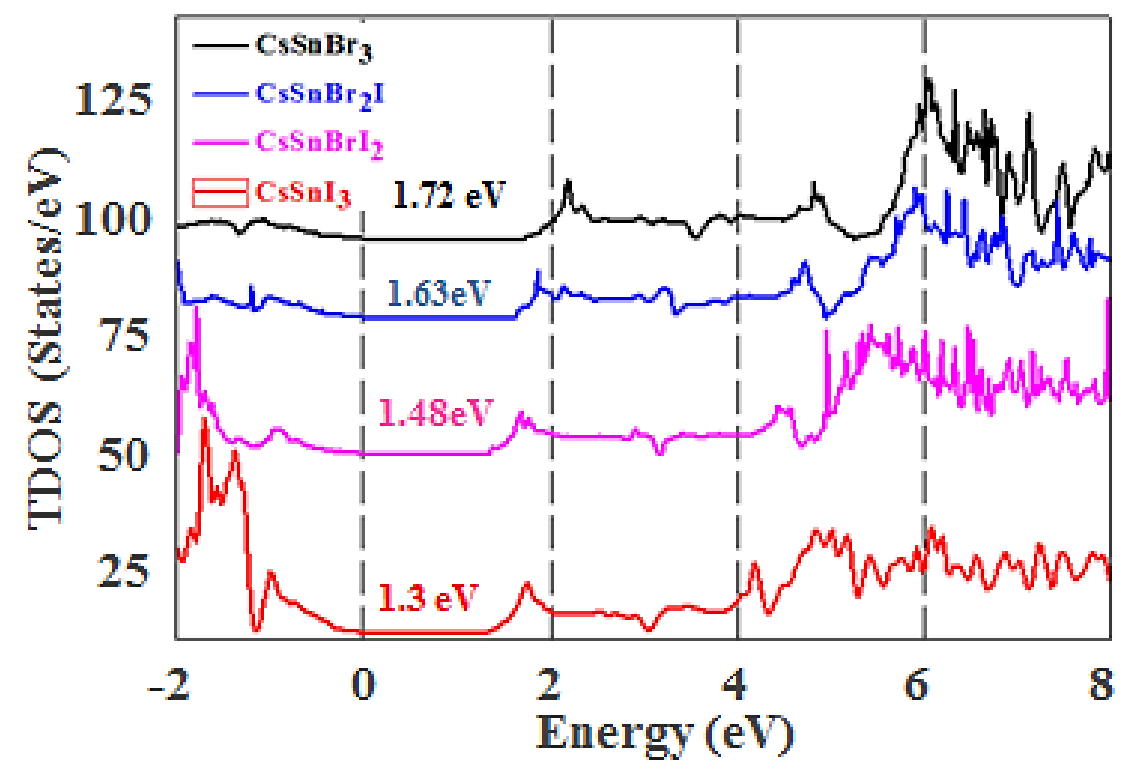

Figure 8. Total density of states for (a) $\mathrm{CsSnBr}_{3}$, (b) $\mathrm{CsSnBr}_{2} \mathrm{I}$, (c) $\mathrm{CsSnBrI}_{2}$ and (d) $\mathrm{CsSnI}_{3}$. The Fermi level is set to 0 
The enhanced density of states for the $\mathrm{CsSnI}_{3}$ and $\mathrm{CsSnIBr}_{2}$ systems means that with an increase in the iodine concentration in the system, the vacancy level in the outer orbitals increases and many places will be available for occupation. The electronic structures of materials near the top of the valence band and the bottom of the conduction band are of vital importance for their electronic transport properties [34-38]. Accordingly, partial densities of states (PDOS) were calculated for the materials under study, which estimate the contribution of each atom and specific electronic states to the formation of the valence and conduction bands near the Fermi level (Figure 9).

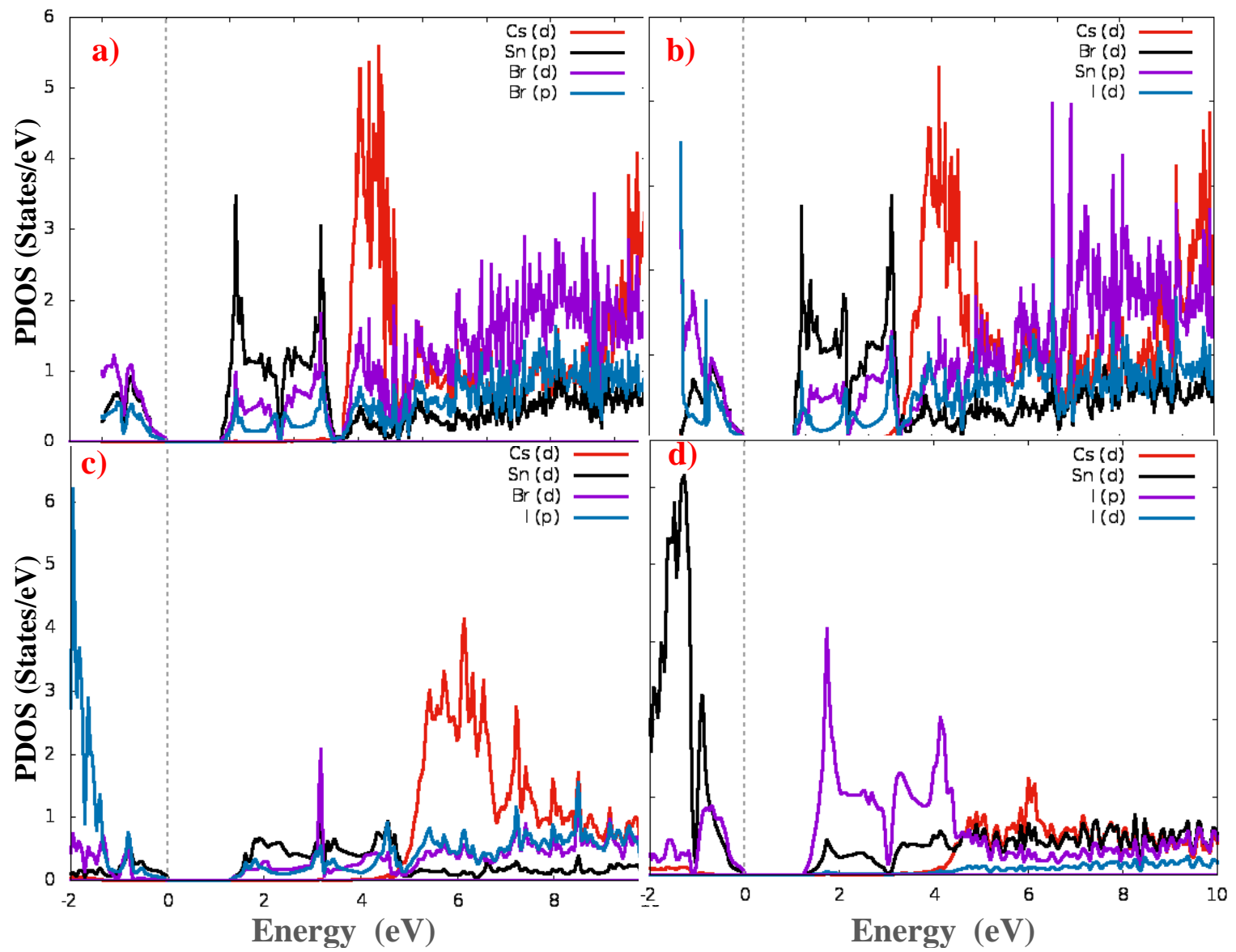

Figure 9. Partial density of states for (a) CsSnBr3, (b) CsSnBr 2 , (c) $\mathrm{CsSnBrI}_{2}$, (d) $\mathrm{CsSnI}_{3}$

The PDOS plots can be explained by two aspects: orbitals, which contribute near the band edges, and the general contribution of states. In the $\mathrm{CsSnBr}_{3}$ system, electrons of the I (d) -state and $\mathrm{Sn}(\mathrm{p})$-state contribute near the valence band (CB) and conduction bands (CB), respectively (Figure 9 (a)). The general contributions to the formation of VB are mainly made by the p-state of $\mathrm{Sn}$ and $\mathrm{I}$, and $\mathrm{Cs}$ (d) to CB. In the case of $\mathrm{CsSnBr}_{2} \mathrm{I}$, an insignificant contribution is made by electrons of all types of atoms (except for Cs) near the VB edge (Figure 9 (b)). There are also small contributions from $\mathrm{Cs}(\mathrm{d}), \mathrm{I}(\mathrm{d}), \mathrm{Sn}(\mathrm{p})$, and $\mathrm{Br}(\mathrm{d})$ - states at the meeting point of $\mathrm{VB}$ and $\mathrm{CB}$. In the formation of electronic states of $\mathrm{CsSnBrI}_{2}$ near the band edges, the contribution is made by the I (p), Br (d) and Sn (d) states (Figure 9 (c)). However, the d-states of Cs electrons have the maximum contribution in the upper part of the CB. The results show that the I (d) and Sn (d) orbitals make the main contributions to the formation of allowed bands (near the band edges) and to the overall contribution of the states of the conduction band $\mathrm{CsSnI}_{3}$. There is also a significant contribution from the d-electron of the Cs atoms (Figure $9(\mathrm{~d})$ ).

Thus, our results can contribute to understanding some of the features of their optical properties, which are important for the practical application of the studied systems, and may turn out to be of interest for researchers searching for materials with predetermined and programmed optoelectronic properties [39-42].

\section{Conclusion}

The structural and electronic properties of displaced perovskite nanocrystals $\mathrm{CsSnBr}_{3}, \mathrm{CsSnIBr}_{2}, \mathrm{CsSnI}_{2} \mathrm{Br}$, and $\mathrm{CsSnI}_{3}$ were studied in the work with the implementation of quantum-chemical calculations. It was found that the band gap decreases linearly with increasing iodine concentration and approaches the optimal band gap for photovoltaic applications. The results obtained can be used by other researchers to model the structure of substances expected to be synthesized, as well as to determine such an important component as "composition-structure-property". 


\section{Declarations}

\subsection{Author Contributions}

Conceptualization, D.D.N. and Kh.T.Kh.; methodology, D.D.N.; software, D.A.Y.; validation, I.T.Kh.; formal analysis, D.D.N.; investigation, D.D.N.; data curation, I.T.Kh.; writing — original draft preparation, D.D.N.; writingreview and editing, I.T.Kh.; visualization, Kh.R.R.; supervision, Kh.R.R.; project administration, Kh.T.Kh.; funding acquisition, Kh.T.Kh. All authors have read and agreed to the published version of the manuscript.

\subsection{Data Availability Statement}

The data presented in this study are available in article.

\subsection{Funding}

The authors received no financial support for the research, authorship, and/or publication of this article.

\subsection{Declaration of Competing Interest}

The authors declare that they have no known competing financial interests or personal relationships that could have appeared to influence the work reported in this paper.

\section{References}

[1] Meng, L., Wu, X. G., Ma, S., Shi, L., Zhang, M., Wang, L., Chen, Y., Chen, Q., \& Zhong, H. (2020). Improving the efficiency of silicon solar cells using in situ fabricated perovskite quantum dots as luminescence downshifting materials. Nanophotonics, 9(1), 93-100. doi:10.1515/nanoph-2019-0320.

[2] Coontz, R. (2013). Science's Top 10 Breakthroughs of 2013. Science, New York, N.Y., USA, 1-4.

[3] Afsari, M., Boochani, A., \& Hantezadeh, M. (2016). Electronic, optical and elastic properties of cubic perovskite CsPbI3: Using first principles study. Optik, 127(23), 11433-11443. doi:10.1016/j.ijleo.2016.09.013.

[4] Wu, T., \& Gao, P. (2018). Development of perovskite-type materials for thermoelectric application. Materials, 11(6), 999.1-32. doi:10.3390/ma11060999.

[5] Yoshikawa, K., Kawasaki, H., Yoshida, W., Irie, T., Konishi, K., Nakano, K., Uto, T., Adachi, D., Kanematsu, M., Uzu, H., \& Yamamoto, K. (2017). Silicon heterojunction solar cell with interdigitated back contacts for a photoconversion efficiency over 26\%. Nature Energy, 2(5), 17032. doi:10.1038/nenergy.2017.32.

[6] Parr, R. G., \& Weitao, Y. (1995). Density-Functional Theory of Atoms and Molecules. In Density-Functional Theory of Atoms and Molecules. Oxford Scholarship Online, Oxford, UK. doi:10.1093/oso/9780195092769.001.0001.

[7] Blaha, P., Schwarz, K., Tran, F., Laskowski, R., Madsen, G. K. H., \& Marks, L. D. (2020). WIEN2k: An APW+lo program for calculating the properties of solids. Journal of Chemical Physics, 152(7), 74101. doi:10.1063/1.5143061.

[8] Hohenberg, P., \& Kohn, W. (1964). Inhomogeneous Electron Gas. Physical Review, 136(3B), B864-B871. doi:10.1103/physrev.136.b864.

[9] Kohn, W., \& Sham, L. J. (1965). Self-Consistent Equations Including Exchange and Correlation Effects. Physical Review, 140(4A), A1133-A1138. doi:10.1103/physrev.140.a1133.

[10] Koller, D., Tran, F., \& Blaha, P. (2011). Merits and limits of the modified Becke-Johnson exchange potential. Physical Review B - Condensed Matter and Materials Physics, 83(19). doi:10.1103/PhysRevB.83.195134.

[11] Marques, M. A. L., Oliveira, M. J. T., \& Burnus, T. (2012). Libxc: A library of exchange and correlation functionals for density functional theory. Computer Physics Communications, 183(10), 2272-2281. doi:10.1016/j.cpc.2012.05.007.

[12] Birch, F. (1947). Finite elastic strain of cubic crystals. Physical Review, 71(11), 809-824. doi:10.1103/PhysRev.71.809.

[13] Kulbak, M., Gupta, S., Kedem, N., Levine, I., Bendikov, T., Hodes, G., \& Cahen, D. (2016). Cesium Enhances Long-Term Stability of Lead Bromide Perovskite-Based Solar Cells. Journal of Physical Chemistry Letters 7(1), 167-172. doi:10.1021/acs.jpclett.5b02597.

[14] Aamlid, S. S., Selbach, S. M., \& Grande, T. (2020). Structural Evolution of Ferroelectric and Ferroelastic Barium Sodium Niobate Tungsten Bronze. Inorganic Chemistry, 59(12), 8514-8521. doi:10.1021/acs.inorgchem.0c00958.

[15] Liu, S., Kim, Y., Tan, L. Z., \& Rappe, A. M. (2016). Strain-induced ferroelectric topological insulator. Nano Letters, 16(3), 1663-1668. doi:10.1021/acs.nanolett.5b04545. 
[16] Chadov, S., Qi, X., Kübler, J., Fecher, G. H., Felser, C., \& Zhang, S. C. (2010). Tunable multifunctional topological insulators in ternary Heusler compounds. Nature Materials, 9(7), 541-545. doi:10.1038/nmat2770.

[17] Davlatshoevich, N. D., Ashur, K. M., Saidali, B. A., Kholmirzotagoykulovich, K., Lyubchyk, A., \& Ibrahim, M. (2022). Investigation of structural and optoelectronic properties of $\mathrm{N}$-doped hexagonal phases of $\mathrm{TiO} 2(\mathrm{TiO} 2-\mathrm{xNx})$ nanoparticles with DFT realization: OPTIMIZATION of the band gap and optical properties for visible-light absorption and photovoltaic applications. In Biointerface Research in Applied Chemistry, 12(3), 3836-3848. doi:10.33263/BRIAC123.38363848.

[18] Nematov, D. Computer analysis of electronic and structural properties of $\mathrm{CsSnI}_{3}: \mathrm{Cl}$ and $\mathrm{CsPbI}_{3}: \mathrm{Cl}$ nanocrystals. Electronic periodical peer-reviewed scientific journal "SCI-ARTICLE.RU" 2019, 76, 187-196.

[19] Doroshkevich, A. S., Nabiev, A. A., Shylo, A. V., Pawlukojć, A., Doroshkevich, ...., Madadzada, A., Bodnarchuk, V. I., \& Ibrahim, M. A. (2019). Frequency modulation of the Raman spectrum at the interface DNA - ZrO2 nanoparticles. Egyptian Journal of Chemistry, 62, 13-20. doi:10.21608/EJCHEM.2019.12898.1806.

[20] Nematov, D. D., Burkhonzoda, A. S., Khusenov, M. A., Kholmurodov, K. T., Doroshkevich, A. S., Doroshkevich, N. V., Zelenyak, T. Y., \& Majumder, S. (2019). Molecular Dynamics of DNA Damage and Conformational Behavior on a Zirconium-Dioxide Surface. Journal of Surface Investigation, 13(6), 1165-1184. doi:10.1134/S1027451019060430.

[21] Nematov, D., Burhonzoda, A., Khusenov, M., Kholmurodov, K., Doroshkevych, A., Doroshkevych, N., Zelenyak, T., Majumder, S., Refaat, A., \& Ibrahim, M. A. (2019). Molecular dynamics simulations of the DNA radiation damage and conformation behavior on a zirconium dioxide surface. Egyptian Journal of Chemistry, 62, $149-161$. doi:10.21608/EJCHEM.2019.12981.1811.

[22] Burkhonzoda, A., Giyosov, S., Nematov, D., Khusenov, M., Kholmurodov, H. (2019). Quanto-mechanical calculation of the electronic structure of $\mathrm{ZrO}_{2}: \mathrm{Ti}^{4+}$ in the framework of the density functional theory. Polytechnic Bulletin. Series: Intellect. Innovation. Investments, 3, 11-17.

[23] Nematov, D. D., Burhonzoda, A. S., Khusenov, M. A., Kholmurodov, K. T., \& Yamamoto, T. (2021). First Principles Analysis of Crystal Structure, Electronic and Optical Properties of CsSnI3-xBrx Perovskite for Photoelectric Applications. Journal of Surface Investigation, 15(3), 532-536. doi:10.1134/S1027451021030149

[24] Burkhonzoda, A.S., Nematov, D.D., Khodzhakhonov, I.T.; Boboshirov, D.I. (2021). Optical properties of nanocrystals of the TiO2-xNx system. SCI-ARTICLE.RU, 92, 176-187.

[25] Burkhonzoda, A.S., Nematov, D.D., Kholmurodov, Kh.T. (2021). Structural and electronic properties of nanoscale thin films based on ZrO2. SCI-ARTICLE.RU, 92, 143-1152.

[26] Nematov, D.D. (2020). Modeling the impact of ionizing radiation on the process of immobilization of biological molecules. SCI-ARTICLE.RU, 81, 12-35.

[27] Nematov, D.D. (2021). Research and optimization of optoelectronic properties of N-doped titanium dioxide (TiO2-xNx) nanoparticles for photovoltaic applications. SCI-ARTICLE.RU, 91, 110-130.

[28] Monkhorst, H. J., \& Pack, J. D. (1976). Special points for Brillouin-zone integrations. Physical Review B, 13(12), 5188-5192. doi:10.1103/physrevb.13.5188.

[29] Clark, S. J., Donaldson, J. D., \& Harvey, J. A. (1995). Evidence for the direct population of solid-state bands by non-bonding electron pairs in compounds of the type CsMIIX3 (M II=Ge, Sn, $\mathrm{Pb} ; \mathrm{X}=\mathrm{Cl}, \mathrm{Br}, 1)$. Journal of Materials Chemistry, 5(11), 1813-1818. doi:10.1039/jm9950501813.

[30] Chen, Z., Wang, J. J., Ren, Y., Yu, C., \& Shum, K. (2012). Schottky solar cells based on CsSnI3 thin-films. Applied physics letters, 101(9), 093901. doi:10.1063/1.4748888.

[31] Jaroenjittichai, A. P., \& Laosiritaworn, Y. (2018). Band alignment of cesium-based halide perovskites. Ceramics International, 44, S161-S163. doi:10.1016/j.ceramint.2018.08.124.

[32] Clark, S. J., \& Donaldson, J. D. (1995). High-temperature Mössbauer studies on 119Sn-enriched caesium tin(II) chlorides and bromides. Journal of the Chemical Society, Dalton Transactions, 17, 2723-2727. doi:10.1039/DT9950002723.

[33] Borriello, I., Cantele, G., \& Ninno, D. (2008). Ab initio investigation of hybrid organic-inorganic perovskites based on tin halides. Physical Review B, 77(23), 235214. doi:10.1103/PhysRevB.77.235214.

[34] Tripathy, A., Behera, M., Rout, A. S., Biswal, S. K., \& Phule, A. D. (2020). Optical, structural, and antimicrobial study of gold nanoparticles synthesized using an aqueous extract of mimusops elengi raw fruits. Biointerface Research in Applied Chemistry, 10(6), 7085-7096. doi:10.33263/BRIAC106.70857096.

[35] Najm, A. S., Moria, H., \& Ludin, N. A. (2020). Areca catechu as photovoltaic sensitizer for dye-sensitized solar cell (DSSC). Biointerface Research in Applied Chemistry, 10(3), 5636-5639. doi:10.33263/BRIAC103.636639. 
[36] Belabbas, M., Marbouh, N., Arbouche, O., \& Hussain, A. (2020). Optoelectronic properties of the novel perovskite materials $\mathrm{LiPb}(\mathrm{Cl}: \mathrm{Br}: \mathrm{I}) 3$ for enhanced hydrogen production by visible photo-catalytic activity: Theoretical prediction based on empirical formulae and DFT. International Journal of Hydrogen Energy, 45(58), 33466-33477. doi:10.1016/j.ijhydene.2020.09.066.

[37] Bartel, C. J., Clary, J. M., Sutton, C., Vigil-Fowler, D., Goldsmith, B. R., Holder, A. M., \& Musgrave, C. B. (2020). Inorganic Halide Double Perovskites with Optoelectronic Properties Modulated by Sublattice Mixing. Journal of the American Chemical Society, 142(11), 5135-5145. doi:10.1021/jacs.9b12440.

[38] Zyuz'kov, G. N., Miroshnichenko, L. A. E., Polykova, T. Y., Stavrova, L. A., \& Simanina, E. V. (2022). Inhibition of adenylate cyclase of regeneration-competent cells of nervous tissue: A novel approach for the treatment of alcoholic encephalopathy. Biointerface Research in Applied Chemistry, 12(2), 1547-1560. doi:10.33263/BRIAC122.15471560.

[39] Folgueras, M. C., Jin, J., Gao, M., Quan, L. N., Steele, J. A., Srivastava, S., Ross, M. B., Zhang, R., Seeler, F., Schierle-Arndt, K., Asta, M., \& Yang, P. (2021). Lattice Dynamics and Optoelectronic Properties of Vacancy-Ordered Double Perovskite Cs2TeX6(X=Cl-,Br-,I-) Single Crystals. Journal of Physical Chemistry C, 125(45), 25126-39. doi:10.1021/acs.jpcc.1c08332.

[40] Irzaman, Rahmawaty, V., Palupi, E. K., Patonah, N., Sumaryada, T., Siskandar, R., Alatas, H., Iqbal, M., Yuliarto, B., Fahmi, M. Z., Rusydi, F., \& Nugroho, W. S. (2021). The effect of photoconductive mole fraction based on thin film BaxSr1-xTiO3 $(\mathrm{X}=0.000 ; 0.125 ; 0.250 ; 0.375 ; 0.500)$ on electrical properties and diffusivity coefficient. Biointerface Research in Applied Chemistry, 11(6), 14956-14963. doi:10.33263/BRIAC116.1495614963.

[41] Liu, J., Qu, J., Kirchartz, T., \& Song, J. (2021). Optoelectronic devices based on the integration of halide perovskites with silicon-based materials. Journal of Materials Chemistry A, 9(37), 20919-20940. doi:10.1039/d1ta04527j.

[42] Mullamuri, B., Sai Sriram Mosali, V., Maseed, H., Majety, S. S., \& Chandu, B. (2021). Photocatalytic activity of heavy metal doped Cds nanoparticles synthesized by using ocimum sanctum leaf extract. Biointerface Research in Applied Chemistry, 11(5), 12547-12559. doi:10.33263/BRIAC115.1254712559. 